\title{
BULLYING NA CONVIVÊNCIA ESCOLAR: UM ESTUDO DE CASO NOS 5os ANOS DO ENSINO FUNDAMENTAL NO COLÉGIO HERMESINDO ALONSO GONZALEZ EM TRÊS LAGOAS-MS
}

\author{
Elizângela Barbosa de Oliveira Ferreira * \\ Terezinha Bazé de Lima**
}

\begin{abstract}
RESUMO: o tema abordado nesta pesquisa foi o Bullying entre os alunos do $5^{\circ}$ ano da Escola Hermesindo Alonso Gonzalez, em Três Lagoas, MS. Assim, o problema apresentado foi: Como combater o bullying na vida escolar? O objetivo da investigação foi compreender os fatores que contribuem para a prática do bullying e avaliar os processos de ação desse fenômeno no contexto escolar, realizados por meio da coleta de dados. Para tanto foi criado $m$ roteiro de entrevistas com gestores e professores do $5^{\circ}$ ano do ensino fundamental da instituição, no período de 27 a 30 de março de 2020. Ao investigar essa experiência, tentamos entender como nossos filhos lidam com essa doença e quais medidas são adotadas pela instituição. No processo de investigação os dados foram analisados, numa perspectiva qualitativa, a fim de compreender e avaliar todo o processo de enfrentamento do bullying. O referencial teórico teve como objetivo, melhor esclarecimento do fenômeno, com estudos já realizados por especialistas sobre o assunto, o que trouxe grandes contribuições sendo apresentados como base do diálogo, autores como: Fante (2011), Chalita (2008) e Pedra (2008). O aprofundamento teórico trouxe como reflexão a extrema importância a ser dada ao fenômeno que se tornou cada vez mais frequente entre os estudantes, resultando muitas vezes em grandes tragédias
\end{abstract}

ABSTRACT: the theme addressed in this research was bullying among 5th year students at Escola Hermesindo Alonso Gonzalez, in Três Lagoas, MS. Thus, the problem presented was: How to combat bullying in school life? The objective of the investigation was to understand the factors that contribute to the practice of bullying and to evaluate the processes of action of this phenomenon in the school context, carried out through data collection. For this purpose, a script of interviews was created with managers and teachers of the 5th year of elementary school of the institution, from March 27 to 30, 2020. In investigating this experience, we try to understand how our children deal with this disease and what measures are adopted by the institution. In the investigation process, the data were analyzed, from a qualitative perspective, in order to understand and evaluate the entire process of coping with bullying. The theoretical framework aimed to better clarify the phenomenon, with studies already carried out by experts on the subject, which brought great contributions being presented as the basis for dialogue, authors such as: Fante (2011), Chalita (2008) and Pedra (2008). The theoretical deepening brought as reflection the extreme importance to be given to the phenomenon that has become more and more frequent among students, often resulting in great tragedies

PALAVRAS-CHAVE: Bullying; Escolares; Combater

KEYWORDS: Bullying; School; Fight 


\section{INTRODUÇÃO}

Este trabalho de conclusão de curso aborda o tema, bullying, foi realizado entre Professores do $5^{\circ}$ ano do ensino fundamental e Gestores da escola particular Hermesindo Alonso Gonzalez de Três Lagoas MS. O tema foi escolhido por ter um crescimento mundialmente alarmante nas últimas décadas com desfechos trágicos.

O objetivo da pesquisa foi ampliar o conhecimento sobre o fenômeno, como ocorre, por quais motivos acontecem e analisar quais métodos a instituição utiliza neste enfrentamento, para que possamos ter uma resposta à seguinte pergunta: Como combater o bullying na convivência escolar?

A metodologia utilizada foi pesquisa descritiva, com abordagem qualitativa, partindo de uma revisão bibliográfica composta por estudiosos, os teóricos selecionados foram Cléo Fante, Gabriel Chalita e José Augusto Pedra, que trouxeram grandes contribuições para a sociedade. Foi realizada uma investigação com observações e roteiro de entrevista entre Professores e Gestores da instituição.

Segundo Fante (2011), Bullying é uma palavra de origem inglesa, usada para definir comportamentos agressivos e antissociais ocorridos principalmente entre escolares. Em alguns países existem outros termos para conceituar, embora esse tipo de violência exista há muitos anos a pouco tempo a sociedade tem se preocupado em entender o fenômeno. Para que se possa encontrar uma solução, é importante conhecer as características dos agressores e vítimas, para que consiga-se traçar um caminho que leve à raiz do problema.

O bullying tem sido muito discutido nos últimos anos, pela mídia social, é preciso avaliar os processos de como vem sendo trabalhado no contexto escolar. É importante conhecer os fatores que desencadeiam comportamentos agressivos que resultam, para que seja encontrada uma maneira eficaz de combatê-lo no ambiente escolar, pois a infância feliz de muitas crianças tem sido roubada e a vida de muitos jovens tem sido ceifadas por um mal silencioso que vem se instalando na sociedade.

\section{DEFINIÇÃO DO TERMO BULLYING}

No Brasil, a Educadora e Pesquisadora Cléo Fante, maior especialista do fenômeno bullying, iniciou suas pesquisas no ano de 2000, inspirada por estudos do Dr Dan Olweus. Segundo FANTE (2015, p. 8):

O termo bullying, de origem inglesa, é utilizado para determinar um fenômeno (uma forma de violência escolar) bastante peculiar, com características definidas e que está em expansão; não indica um conflito normal ou uma simples briga entre estudantes, mas sim um 
tipo de comportamento que dá origem a ataques (físicos, psicológicos, sexuais) de forma intencional e repetitiva, contra alguém que, geralmente, não tem condições de se defender. (FANTE, 2015, p. 8).

Gabriel Chalita um advogado, jurista, professor, escritor e político brasileiro também em uma de suas obras, define bullying:

A palavra bullying é um verbo derivado do adjetivo inglês bully, que significa valentão, tirano. É o termo que designa o hábito de usar a superioridade física para intimidar, tiranizar, amedrontar e humilhar outra pessoa. A terminologia é adotada por educadores, em vários países, para definir o uso de apelidos maldosos e toda forma de atos desumanos empregados para atemorizar, excluir, humilhar, desprezar, ignorar e perseguir os outros. (CHALITA, 2008, p. 81).

Fante (2011), relata que a maioria dos pesquisadores tem tido dificuldades de encontrar termos correspondentes ao sentido da palavra bullying em diversos idiomas, no Brasil, é utilizado esse termo por ser empregado na maioria dos países.

De acordo com Fante (2011), alguns países usam outras terminologias para conceituar comportamentos agressivos, como na Noruega e Dinamarca se usa o termo Mobbing Suécia e Finlândia, mobbning; na França, harcèlement quotidién; na Itália, prepotenza ou bullismo; no Japão, é conhecido como yjime; Alemanha, agressionen unter chulern; Espanha, acaso amenaza entre escolares; Portugal, maus-tratos entre pares.

Assim sendo, por definição universal, bullying é um conjunto de atitudes agressivas, intencionais e repetitivas que ocorrem sem motivação evidente, adotado por um ou mais alunos contra outros, causando dor, angústia e sofrimento. Insultos, intimidações, apelidos cruéis, gozações que magoam profundamente, acusações injustas, atuação de grupos que hostilizam, ridicularizam e infernizam a vida de outros alunos levando-os à exclusão, além de danos físicos, morais e materiais, são algumas das manifestações do comportamento bullying. (FANTE, 2011, p. 28).

O que antigamente era considerado uma brincadeira de mal gosto entre colegas, ou apenas um desentendimento comum entre os jovens, hoje é denominado bullying, algo grave, que se repete constantemente com a mesma pessoa, trazendo sentimentos negativos, de inferioridade, tristeza, que resultam muitas vezes em grandes tragédias. Tal fenômeno sempre existiu, mas pouco se falava ou sabia a respeito, não havia tantos incidentes, 
porém, nos últimos anos, o número de casos tem crescido, de maneira exorbitante no Brasil e no mundo, com resultados alarmantes.

Por ser algo que tem acontecido com frequência nas escolas do mundo todo, pais, educadores, psicólogos e estudiosos da área têm buscado entender e explicar o fenômeno na tentativa de encontrar uma solução, ser aniquilado, ou amenizado, para um melhor desenvolvimento uma boa convivência em sociedade, pois é um mal que tem trazido sérios danos não só aos envolvidos diretamente, mas a todos familiares.

Chalita (2008), afirma que o fenômeno não escolhe classe social, independe de cultura, país; pode ocorrer tanto em escolas públicas quanto particulares, e se faz presente entre grupos de crianças e jovens.

\footnotetext{
Nas escolas, é um fenômeno complexo, muitas vezes banalizado e confundido com agressão e indisciplina. Exige observação atenta e presença constante, pois, normalmente, as vítimas são aterrorizadas em áreas da escola com pouca ou nenhuma supervisão. Estratégia premeditada, que contribui para que a vítima seja desacreditada. (CHALITA, 2008, p.81).
}

Há a necessidade de diferenciar o bullying de um comportamento agressivo em que há desentendimentos entre escolares decorrente da fase de desenvolvimento em que estão; por isso, é importante a conceituação do bullying, e estudos vêm sendo feito em relação ao fenômeno, para que todos possam saber identificar, para que algo possa ser feito antes que desencadeie danos mais sérios.

\section{HISTÓRICO DO FENÔMENO}

O bullying é um fenômeno muito antigo, porém não era visto como um problema que pudesse causar sérios danos à infância e a juventude; era visto apenas como uma brincadeira típica da adolescência, do desenvolvimento da criança e do jovem; nada que merecesse atenção especial. Na década de 70 a sociedade começou a se interessar pelos problemas resultantes desse mal.

Segundo Fante (2011), a Suécia foi o primeiro país em se preocupar com o fenômeno e logo essa preocupação se estendeu por vários outros países, havia uma certa inquietação e preocupação por parte de educadores em relação às consequências entre agressores e vítimas, mas nada que mobilizasse as autoridades educacionais a tomarem uma atitude em prol do combate ao bullying. 
Muito pouco se falava ou sabia a respeito; todo comportamento agressivo entre escolares era visto como uma fase do desenvolvimento da criança e do adolescente, nada que levantasse suspeitas de que algo muito maior poderia estar camuflado.

Fante (2011) diz que no final de 1982, na Noruega três crianças de idade entre 10 e 14 anos, suicidaram-se, isto, repercutiu nos meios de comunicação da época, causando grande comoção de toda sociedade, motivo pelo qual o Ministério da Educação da Noruega, em 1983, fez uma campanha em escala nacional contra o bullying.

De acordo com Fante (2011), esse acontecimento com desfecho trágico foi o ponto inicial para investigações da origem das tendências suicidas entre adolescentes, Espanha, Canadá, Portugal, Inglaterra e Noruega se tornaram os pioneiros, considerados fundamentais pela Organização Mundial de Saúde (OMS), campanhas antibullying no mundo todo foram criadas.

O Dr Dan Olweus, pesquisador sueco, professor de psicologia da Universidade de Bergen na Noruega foi quem criou parâmetros que facilitassem a identificação do bullying. Em 1970, iniciou um projeto chamado Programa de Prevenção Olweus Bullying (OBPP), considerado o primeiro estudo científico de bullying no mundo; ele é reconhecido como pioneiro e fundador de pesquisas sobre o bullying, escreveu o livro "Bullying na Escola: O Que Sabemos e o Que Podemos Fazer" já foi traduzido em 15 línguas diferentes, recebeu prêmios por seu trabalho de pesquisa e prevenção, trouxe grandes contribuições para a sociedade. Infelizmente, o fenômeno só passou a ser observado com mais atenção depois de acontecimentos como suicídios de vítimas de bullying e ataques a escolas.

Passou-se a falar mais sobre o tema, na mídia televisionada e nos meios eletrônicos; foi ficando mais conhecido pela população em geral. O tema chegou ao Brasil no fim de 1990, início de 2000, enquanto em outros países já se estudava mais a fundo o fenômeno, já era notório a preocupação com as consequências.

Segundo menciona Chalita (2008), as investigações, desenvolvidas na Europa, repercutiram no Brasil com certo atraso, foram realizados vários estudos baseados nas iniciativas europeias por profissionais em 4 escolas do Rio Grande do Sul, que contribuíram para o mapeamento da violência escolar no Brasil.

Fante (2011) revela que o Brasil está pelo menos 15 anos atrasado em relação à Europa no que se refere a estudos sobre o bullying,

Chalita (2008) em sua obra diz:

[...] mesmo sendo tão antigo e já tendo sido objeto de preocupação e investigação por ter comprometido a vida de estudantes, no passado, nada se sabe concretamente sobre o bullying antes da 
década de 1970. Foi somente com pesquisas realizadas em 1972 e 1973, na Escandinávia, que as famílias perceberam a seriedade dos problemas decorrentes da violência escolar. (CHALITA, 2008, pág. 100).

Chalita (2008), menciona um estudo desenvolvido pela educadora Cléo Fante em São José do Rio Preto, interior paulista, nos anos de 2002 e 2003, foi extremamente importante, envolveu cerca de 2 mil alunos de oito escolas da rede pública e privada, em que foi permitido traçar o perfil das vítimas no Brasil. Portanto, é notório que há um enorme esforço por parte dos estudiosos esclarecer o fenômeno e propagar suas características para que assim, a sociedade em geral, saiba da gravidade da situação que pode ocasionar na vida das pessoas envolvidas.

A população precisa estar atenta e junto com a comunidade escolar desenvolver medidas preventivas, para que um mal maior não venha recair sobre ela. A educadora Cleo Fante criou o Programa Educar para a Paz, foi o primeiro programa de combate ao bullying no Brasil, desenvolvido em uma escola pública de São José do Rio Preto com resultados surpreendentes, pois foi comprovada a redução de comportamentos agressivos como o bullying entre os alunos da escola em que o programa foi implantado.

Esse programa por nós idealizado, desenvolvido e implantado em uma escola da rede pública de ensino de São José do Rio Preto, é composto de estratégias psicopedagógicas e socioeducacionais que visam à intervenção e à prevenção da violência nas escolas, com enfoque específico na redução do fenômeno bullying entre os escolares. (FANTE, 2011, p. 90).

Fante (2011), menciona que embora tenha estudado e realizado pesquisas com resultados satisfatórios, tem alcançado um universo pequeno de escolas, pois não contam com patrocínio ou qualquer tipo de incentivo. Para levar conhecimento sobre o bullying ao maior número de pessoas possível, tentando, desta forma, mostrar à sociedade a relevância desse fenômeno.

Durante esse tempo, temos nos empenhado no combate ao bullying com o intuito de conscientizar pais, professores, alunos, psicólogos, psiquiatras, pediatras e demais profissionais envolvidos no processo educacional. Procuramos demonstrar que é possível reduzir os índices de sua manifestação por meio das estratégias que desenvolvemos e sugerimos no Programa Educar para a Paz. (FANTE, 2011, p. 50).

Apesar do trabalho árduo e incansável de muitos no combate e propagação do fenômeno, mesmo sendo algo tão antigo quanto a escola, infelizmente ainda há muito a se fazer, pois 
o tema em muitos países por exemplo, é algo novo, e necessita urgentemente que a sociedade consiga enxergar a extrema relevância do fenômeno.

As consequências do bullying segundo Fante (2011), atinge não só as vítimas, mas todos os envolvidos até mesmo indiretamente podem ou não superar os traumas sofridos, que podem trazer sérios prejuízos ao seu desenvolvimento pessoal, futura constituição familiar, criação dos filhos, além de trazer danos à saúde mental e física.

Chalita (2008), diz algo que chama a atenção:

O bullying é uma violência que cresce com a cumplicidade de alguns, com a tolerância de outros e com a omissão de muitos. E se transforma em ferocidade camuflada, compondo um cenário que nos intima, enfim, a sair do conformismo, do pessimismo e da apatia das "cavernas" edificadas para nos proteger da realidade. Uma realidade grave e muda, com consequências alarmantes. (CHALITA, 2008, p.109).

O bullying tornou-se um problema global, as pessoas estão morrendo, crianças e jovens estão tendo suas vidas interrompidas por um mal que ninguém vê, silencioso e devastador; é com urgência que a sociedade deve agir para tomada de decisão; as vítimas precisam ser percebidas e ouvidas. É um mal que está crescendo; há como fazer algo que amenize está situação.

Comprovado por estudos de Olweus em muitas escolas dos países em que foi aplicado o método sugerido por ele. No Brasil, a educadora Cleo Fante comprovou a eficácia do Programa Educar para Paz, que obteve uma redução considerável nas escolas onde foi aplicado. Portanto, é possível, há esperança, mas é necessário que esse fenômeno seja visto com um olhar mais atento por toda a sociedade e lhe dada a devida importância, pois se expande a cada dia. Chalita (2008), diz que ninguém nasce com vontade de matar, desequilibrado por vontade própria; é necessário despertar o que faz parte da natureza humana, a solidariedade está no íntimo humano, mas para vir a florescer, é preciso estimular.

É imprescindível que haja uma parceria com a família no combate ao bullying, pois é a base de uma sociedade saudável, sem a qual torna-se impossível vencer esta luta; há a necessidade de um trabalho em conjunto, não é algo delegado somente à escola por ser o local de maior propagação do bullying, mesmo tendo em mãos maior autonomia no combate dentro de suas dependências. O bullying não é superficial, tem raízes profundas dentro das pessoas que se tornam agressoras. Gabriel Chalita, em uma de suas obras, escreveu sobre a importância da família na formação da criança: 
A vida familiar é o primeiro contato do cidadão com o mundo. $\mathrm{O}$ exemplo materno e o paterno, a alimentação, os sons recebidos do mundo externo, os mitos que começam a se formar, os medos, o aprendizado da linguagem. Esse processo continua por toda a vida. Mesmo que as relações familiares mudem, que os filhos decidam morar sozinhos, não há como negar que por toda a vida se carrega a estrutura básica obtida na formação da infância, que se dá fundamentalmente na família. (CHALITA, 2004, p.125 apud MAURO, MARGARETE GABARRON, 2010).

É na família que acontece o primeiro contato social; no seio familiar que se inicia a construção de valores afetivos, de como se relacionar com o outro. É necessário que a família seja presente nesse processo de desenvolvimento da criança, dando a ela o suporte necessário para um crescimento e desenvolvimento saudável; por isso, a família é importante aliada no combate ao bullying.

É importante que todos estejam atentos, para que se possa evitar transtornos no desenvolvimento da criança, tragédias futuras conforme o caso de alguns países, inclusive o Brasil. Em abril de 2011, na escola municipal Tasso da Silveira, no Realengo, estado de São Paulo, um ex-aluno invadiu a escola e matou 12 crianças e se matou em seguida; em outubro de 2017, um menino de 14 anos entrou no colégio Goyazes em Goiânia e matou 2 alunos, dizendo ser vítima de bullying.

Em Columbine, Colorado, Estados Unidos, no dia 20 de abril de 1999, 2 adolescentes, um de 17 anos e o outro de 18 anos, entraram armados numa escola e mataram 13 pessoas, deixando mais de 20 feridos; em seguida, cometeu suicídio; em 13 de março de 2019, na escola Raul Brasil em Suzano, que fica no estado de São Paulo, um aluno de 17 anos e um amigo de 25, invadiram a instituição, deixando 10 mortos incluindo eles, e 11 feridos. (VEJA, 2019), apenas alguns casos de tragédias ocorridas pelo mundo decorrentes do bullying.

A realidade de acontecimentos trágicos provenientes do fenômeno vem crescendo no mundo todo e medidas de combate ao bullying precisam ser tomadas em todas as escolas e a família precisa se preparar para esse combate, juntamente com a escola, para que essa realidade venha mudada, e novas tragédias não venham a acontecer. 


\section{CARACTERÍSTICAS DOS AGRESSORES E DAS VÍTIMAS}

É importante a identificação do perfil tanto dos agressores quanto das vítimas, pois ambos sofrem e precisam ser tratados; é necessário estar atento a qualquer sinal entre alunos, não só observando, mas ouvindo. Isso pode amenizar conflitos e possíveis agressões desencadeados pelo bullying. Geralmente os agressores são alunos com problemas familiares, desassistidos pela família, criados com pouco ou nenhum afeto; lares desestruturados tendem a prejudicar o desenvolvimento da criança.

Segundo Chalita (2008), mesmo a uma família desestruturada e escassa de afeto, não se pode atribuir culpa total a ela, pois, desta forma, estaria rotulando famílias inteiras, descarregando a culpa do fenômeno bullying, porém não é algo que deva ser deixado de lado; merece atenção. A falta de assistência pela família em relação à criança, implica em muitas dificuldades que serão enfrentadas por essa criança, porém ainda assim, não se pode afirmar que uma criança mal assistida pela família resultará em um futuro agressor, mas há grandes chances.

Há muitas vidas construídas com sucesso, com laços fortalecidos, onde paira o amor, a união, a cumplicidade, a compaixão pelo próximo, provindas de adultos que foram crianças solitárias, desassistidas pela família, abandonadas à própria sorte, porém escolheram caminhos diferentes para trilhar; levantaram e lutaram para construir sua vida, seu futuro e dar à sua família tudo que não teve.

$\mathrm{O}$ perfil dos agressores segundo Chalita:

Os agressores, normalmente, são alunos populares, que precisam de plateia para agir. Reconhecidos como valentões, oprimem e ameaçam suas vítimas por motivos banais, apenas para impor autoridade. Sentem-se realizados e reconhecidos com o feito. Mantêm um grupo em torno de si, com o qual divide a responsabilidade e por quem se sentem apoiados e fortalecidos. Aqueles que gravitam ao redor do líder ou líderes também são considerados agressores. (CHALITA, 2008, p. 87).

O agressor sente a necessidade de chamar atenção, como se cada atitude ruim em relação ao colega o tornasse mais forte, mais respeitado, mais conhecido e admirado por outros, mesmo negativamente; tem necessidade de ser sempre o melhor, o mais forte é gritante e não o incomoda o fato de ser visto como o carrasco da escola, desde que seja visto.

O praticante do fenômeno precisa de ajuda; ele sofre interiormente e ninguém vê, assim como a vítima; ambos necessitam de ajuda, precisam ser assistidas por profissionais para que consigam sair desse mal que os consomem. 
Segundo Chalita (2008), as vítimas são escolhidas sem um motivo evidente, um comportamento diferente do comum, ou por não ter habilidade em algum esporte, ou uma deficiência física, ou por diferenças culturais, descendência, ou estar fora do padrão de beleza considerada pelo grupo.

Qualquer fator considerado pelo agressor incomum, pode fazer nascer uma vítima do fenômeno. As características mais comuns entre as vítimas de bullying, são relacionadas à aparência física. Geralmente, segundo Fante (2011), são crianças ou adolescentes considerados mais fracos fisicamente, que não conseguem se defender sozinhos nem se impor. Crianças tímidas, são vistas pelo agressor como "presas fáceis".

Algumas são consideradas vítimas provocadoras, são aquelas que provocam o outro, porém não consegue lidar com as reações agressivas do colega.

As consequências para as vítimas de bullying são seríssimas, pois se não conseguirem superar o trauma sofrido, possivelmente terá seu desenvolvimento psíquico prejudicado, Fante nos mostra as consequências que acompanham as vítimas:

[.... Isso afetará o seu comportamento e a construção dos seus pensamentos e de sua inteligência, gerando sentimentos negativos e pensamentos de vingança, baixa autoestima, dificuldades de aprendizagem, queda do rendimento escolar, podendo desenvolver transtornos mentais e psicopatologias graves além de sintomatologia e doenças de fundo psicossomático, transformandoa em um adulto com dificuldades de relacionamento e com outros graves problemas. (FANTE, 2011, p. 79).

Por motivos como os já citados, é extremamente importante todos ficarem atentos, tanto a família como toda a comunidade escolar, para que se possa perceber qualquer sinal de agressão que venha a desencadear situações semelhantes ao bullying, para que assim, sejam combatidas, por meio de estratégias eficazes, antes que o pior venha a acontecer.

\section{COLETA DE DADOS E RESULTADOS}

Foi realizada a pesquisa no Colégio Hemesindo Alonso Gonsalez, em Três Lagoas, Mato Grosso do Sul, criamos um questionário com a equipe gestora da unidade escolar e professores do $5^{\circ}$ ano do ensino fundamental, com a finalidade de averiguar como vem sendo trabalhado a questão do bullying, e como combatê-lo na convivência escolar.

Quadro 1: Questionário realizado com a Coordenadora do Ensino Fundamental 1 
1) A instituição tem adotado algum programa, projeto ou ação de prevenção e combate ao bullying? Qual? Como é feita a conscientização?

Sim, adotamos o programa: Escola da Inteligência, que trabalha a educação socioemocional das nossas crianças; é desenvolvido pela professora de sala com material que disponibilizamos para toda a turma. Sempre temos reuniões com toda equipe e famílias para estarmos proporcionando o melhor para nossos alunos.

2) O Programa ou ação adotado tem trazido resultados positivos?

Com certeza, não temos situações de bullying entre nossos alunos.

3) Toda comunidade escolar juntamente com a família está incluída neste processo? Como ou de que forma?

Sim, além das reuniões com os educadores, sempre proporcionamos encontros da família na escola.

Fonte: A Pesquisa (2020)

A equipe escolar entrevistada, mostrou-se inteiramente atenta e preparada para lidar com o bullying, pois já preocupados com o que vem acontecendo em decorrência do fenômeno, têm estudado e preparado toda a comunidade escolar juntamente com a família para esse enfrentamento.

Quadro 2 - Questionário realizado com os Professores

1- Você já incluiu em suas aulas, o assunto sobre o bullying e a importância do acolhimento e respeito entre os alunos?

Professor A: Esse assunto está sempre presente em sala de aula; os alunos têm aula do Proerd, que trata sempre deste tema, drogas e violência e os alunos aqui são muito amigos, pois caminham juntos desde o infantil.

Professor B: Incluo esse tema em minhas aulas, quando desavenças entre a turma, paraliso minha aula, e ensino sobre respeito e companheirismo.

Professor C: Sim, sempre falamos do assunto

2- Já presenciou algum caso de bullying entre os alunos do $5^{\circ}$ ano?

Professor A: Nunca presenciei nada do tipo entre a turma, apenas desavenças comuns a idade

Professor B: Não na atual escola, somente discussões comuns.

Professor C: Nesta escola, não

3- Que estratégias você tomaria ao presenciar uma situação de bullying?

Professor A: Além de conversar com toda a turma, encaminharia o caso à coordenação.

Professor B: Pararia minha aula e falaria a importância de acolher os colegas e sobre o respeito ao próximo. 
Professor C: Além de conversar com os envolvidos, levaria o caso para coordenação, para que solucionassem o problema da melhor maneira possível.

\section{4- Você pode descrever algum exemplo para ilustrar os nossos dados?}

Professor A: Os casos de desentendimentos resolvemos com conversa, como disse antes não presenciei na sala nenhuma situação de bullying.

Professor B: Tínhamos em sala uma aluna muito quieta, não interagia com a turma, os outros colegas a achavam muito incomum. Mas conversei com toda a turma sobre a valorização da amizade e respeito ao próximo e passei o caso à coordenação. Porém isso não acontecia com frequência, não podendo ser considerado bullying.

Professor C: Já aconteceu brigas entre colegas, mas não bullying, encaminhei para a coordenação a fim de evitar novas ocorrências.

\section{5- Quais as medidas que a Escola tem hoje para que o bullying não seja uma prática} na convivência dos alunos?

Professor A: Além do Proed, temos o programa: Escola da Inteligência que trabalha a educação socioemocional no ambiente escolar.

Professor B: Os professores desta unidade escolar são orientados a trabalharem essa realidade com seus alunos.

Professor C: Temos o Proerd e EI (Escola da Inteligência)

Fonte: A Pesquisa (2020)

Os professores entrevistados, também se mostraram preocupados e atentos a qualquer indício que possa acarretar consequências semelhantes ao fenômeno; todos têm participado de reuniões em que o problema é discutido, sempre no intuito de fazer o melhor por seus alunos, estando atentos, a todo instante, para que não passe despercebido, atitudes negativas que venha trazer consequências desastrosas como as que vêm sendo noticiadas na mídia do mundo todo.

\section{CONSIDERAÇÕES FINAIS}

Este artigo teve como principal objetivo analisar como a escola e toda a equipe gestora vem se comportando diante deste mal, que vem se manifestando de forma violente na sociedade.

Constatou-se pela pesquisa, que no Colégio Hermesindo Alonso Gonzalez toda a equipe escolar tem se mostrado preocupada e atenta a qualquer evidência que possa vir a se transformar em bullying. Reconhecem a importância de se trabalhar essa temática com seus alunos e com toda a comunidade escolar, incluindo a família, que precisa fazer parte desse processo educacional. Pensando, a escola adquiriu um programa denominado: 
Escola de Inteligência, que trabalha o socioemocional, contribuindo com o desenvolvimento da empatia, pensamento crítico, autoconhecimento entre outros.

Os professores participam de reuniões e palestras que abordam o tema juntamente com a família, e ministram aulas semanais ensinando seus alunos sobre a importância da empatia, solidariedade, companheirismo e cooperação.

Todos os teóricos em que foi embasada esta pesquisa, seguem a mesma linha de raciocínio, acreditam que a família precisa aprender a educar e a amar seus filhos. A luta contra o bullying não é só da escola, ainda que a maior incidência seja em suas dependências, o bullying é algo muito maior, está enraizado dentro das pessoas que sofreram dentro de seus lares, com famílias desestruturadas, que não dão amor e valor aos seus filhos; portanto, essa luta começa dentro de casa e a família de mãos dadas com a escola se tornam mais fortes no combate ao bullying.

O interesse pelo tema surgiu a partir da observação da necessidade que ainda se faz presente na sociedade, com tantos casos de massacres em escolas acontecendo pelo mundo.

É de suma importância que se discuta sobre o tema, que seja abordado nas escolas, nas famílias, é necessário trabalhar o socioemocional das nossas crianças para que se desenvolvam em sua plenitude, com qualidade, transformando-se em seres humanos melhores, todos são capazes, é necessário estar com olhares atentos e ensinar nossos filhos a amar.

\section{REFERÊNCIAS}

CHALITA, Gabriel. Pedagogia da amizade. bullying: o sofrimento das vítimas e dos agressores. 5. ed. São Paulo: Gente, 2008. 281 p.

De Columbine a Realengo: os massacres em escolas que chocaram o mundo. Disponível em: https://veja.abril.com.br/mundo/de-columbine-a-realengo-os-massacres-em-escolasque-chocaram-o-mundo/ Acesso em: 26 de janeiro de 2020

FANTE, Cleo. Fenomeno bullying: Como prevenir a violencia e educar para a paz. 6 . ed. Campinas, SP: Verus Editora, 2011. 224 p. 
FANTE, Cleo; PRUDENTE, Neemias Moretti. Bullying em Debate. São Paulo: Editora: Paulinas, 2015.

FANTE, Cleo; PEDRA, José Augusto. Bullying escolar: Perguntas e respostas. Porto Alegre Ed. Artmed, 2008.

MAURO, Margarete Gabarron. (2010). Bullying: Pensando alternativas e propostas para combater essa violência no contexto escolar. Disponível em: http://www.diaadiaeducacao.pr.gov.br/portals/cadernospde/pdebusca/producoes pde/20 10/2010_uem_ped_pdp_margarete_gabarron_mauro.pdf. Acesso em: 27 de agosto de 2019.

*Acadêmica do Curso de Pedagogia do Centro Universitário da Grande Dourados - UNIGRAN. E-mail: elizferreira.tls@gmail.com

**Orientadora desta pesquisa, Professora Dra Terezinha Bazé de Lima, da UNIGRAN Dourados/MS no curso de Pedagogia, pesquisadora da FUNLEC/UNIGRAN e FUNDECT/MS colaboradora e orientadora de pesquisa. E-mail: bazelima@unigran.br. 